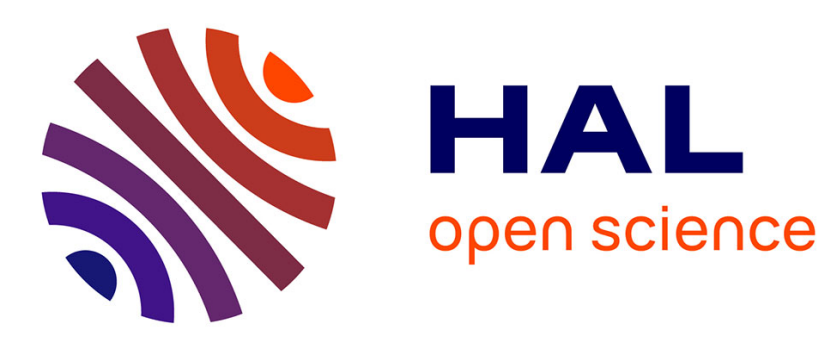

\title{
Altered maternal psychological profile as health risk factor in poor urban infants
}

\author{
M. Araya, J. Espinoza, B. N. Zegers, S. Cruchet, O. Brunser, Derek \\ Humphreys, Cl Fernandez
}

\section{- To cite this version:}

M. Araya, J. Espinoza, B. N. Zegers, S. Cruchet, O. Brunser, et al.. Altered maternal psychological profile as health risk factor in poor urban infants. Acta Paediatrica, 1996, 85 (10), pp.1213-1216. 10.1111/j.1651-2227.1996.tb18231.x . hal-02525035

\section{HAL Id: hal-02525035 \\ https://hal.science/hal-02525035}

Submitted on 30 Mar 2020

HAL is a multi-disciplinary open access archive for the deposit and dissemination of scientific research documents, whether they are published or not. The documents may come from teaching and research institutions in France or abroad, or from public or private research centers.
L'archive ouverte pluridisciplinaire HAL, est destinée au dépôt et à la diffusion de documents scientifiques de niveau recherche, publiés ou non, émanant des établissements d'enseignement et de recherche français ou étrangers, des laboratoires publics ou privés. 


\title{
Altered maternal psychological profile as health risk factor in poor urban infants
}

\author{
M Araya ,J Espinoza , B Zegers², S Cruchet , I Brunser , I Humphreys̊ and CL Fernandez \\ Institute of Nutrition and Food Technology ${ }^{1}$, University of Chile; School of Psychology, Gabriela Mistral University; Fellow, Department of \\ Psychiatry, Eastern Division, School of Medicine, University of Chile
}

\begin{abstract}
Acta Prediatr 1996;85:1213-6. Stockholm.
Totest the hypothesis that the increased health risk of children selected by a previously calculated and validated predictive model is associated with some maternal psychological characteristics, the universe of 107 mothers of children selected by this mode) was evaluated by means of Goldberg's General Health Questionnaire (GHQ-30), Raven (Ra) and Rorschach (Ro) tests; 37.4\% were cases according to GHQ-30, 80.9\% were <50th percentile in Ra and 85\% exhibited deviant responses in Ro tests. Children whose mother's IQ was $<50$ th percentile suffered more episodes of total morbidity (Tm) and of diarrhoea $(p=0.0364)$. Children whose mothers were normal in $\operatorname{Ro~had~Jess~} \operatorname{Tm}(p=0.0364)$ and fewer respiratory symptoms $(p=0.0300)$ and tended to have less diarrhoea $(p=0.0690)$. In poor urban families in Santiago psychological maternal characteristics are associated with an increased health risk for the infants. Supportive programmes should consider both biological characteristics of the infants and maternal psychological needs. Diarrhoea, infants, maternal neurosis, respiratory episodes, risk
\end{abstract}

The epidemiological profile of infantile health problems is changing in Chile towards that of developed countries $(1,2)$. Some years ago, when diarrhoeal disease was the second cause of morbidity among urban poor infants, we demonstrated that diarrhoeal episodes were not homogeneously distributed, with a proportion of infants suffering considerably more episodes than the mean for the group(3). In an effort to better identify this group, a predictive model was calculated by logistic regression $(4,5)$. The hypothesis was that application of such a model and the follow-up of high-risk infants would teach us about the risk factors involved and would result in specific programmes for this segment of population.

Surveys of children selected by the model showed that their risk was not explained by variables related to the host or the environment (3-6). Instead, data obtained during home visits and at a Field Station about some forms of maternal behaviour (unpublished) led us to the hypothesis that maternal neurotic symptoms could contribute to the higher risk of disease in their offspring. A preliminary evaluation by means of the 30-question General Health Questionnaire (GHQ-30) $(7,8)$ showed a twofold increase of cases among mothers of highrisk children compared with a non-selected group of mothers from the same population (9).

The objective of the study reported here was to describe the psychological profile of mothers of children at risk (selected by the predictive mode!) and to relate this with their health indicators during the first year of life.

\section{Subjects and methods \\ The predictive instrument}

The predictive instrument was defined by six variables selected by the logit programme (10-12): a previous diarrhoeal episode, administration of antibiotics during these episodes, a history of previous hospitalization, the day of first consultation to the health system, the number of live children, and whether milk feedings were stopped during the first $48 \mathrm{~h}$ of diarrhoea (4). Each variable was assigned a score on the basis of its regression coefficient. A eut-off point of $20 />20$ points was established by the programme to define cases. The model was pretested in mothers whose children received medical care at the La Faena Health Centre. At the time of this study the model had been applied four times and had repeatedly selected children who suffered four to five times more diarrhoeal and respiratory episodes than their unselected peers from the same area $(5,6)$.

\section{Subjects and design}

The study was carried out at the La Faena Health Centre, in East Metropolitan Santiago, where the infant mortality rate and other health indicators are 
among the worst in the city and where during the last 10 years we have carried out a number of field studies (4-6, 13, 14).

In June 1990 and in January and June 1991 the predictive form was applied to all families who had an infant registered at this Centre. Experience from previous studies indicated that this detected up to $20 \%$ of the families as "at risk". When the score exceeded 20 points mothers were invited to accept a weekly home visit and to attend two interviews during which tests (see below) would be applied. Three cohorts of children ( $n$ 45 each as an average), who represented the universe of high-risk children during the study period, were formed and surveyed consecutively for 6 months each. Thus, children between 12 and 18 months of age were kept under surveillance and seasonal variations of diarrhoeal and respiratory episodes were covered.

\section{Procedures}

Data about socio-economic stratum $(15,16)$ and demographic characteristics were obtained during home visits and ail symptoms present in the index children since last seen were recorded. Episodes were defined as the number of days during which mothers reported symptoms of acute infectious illnesses. In this way, total morbidity (any symptoms of acute infectious disease), diarrhoeic and respiratory episodes were registered and their duration calculated. A paediatrician and a nurse who belonged to the research team treated sick children at our Field Station. Besides, each child was weighed and measured monthly. Nutritional parameters were expressed as Weight/Age (W/A), Length/Age (L/A) and Length/Weight (L/W) (17).

During the first interview mothers answered the GHQ-30. This test is used in community studies to identify subjects who may have neurotic disorders $(7,8)$. The cut-off point to define cases was set at 12 points according to results of previous Chilean and international studies $(9,18-22)$. During the second interview the test of progressive matrices (Raven), which evaluates intellectual capacity (IQ) following a theoretical bifactorial mode) of intelligence, was self administered (23). It was chosen because it is considered to be free of cultural contamination; results were expressed as centile distribution. Afterwards, during the same session, the Rorschach test was applied (24); this projective test is frequently used on clinical grounds to assess neurotic and psychotic conditions; it provides a profile of personality, allowing intrapersonal and interpersonal comparisons as well as contrasting with criteria of normalcy established for adult population $(24,25)$. A formal analysis of categories was used to define normal and abnormal responses. The scoring system summarizes the responses according to localization (selected area), perceptual qualities that determines the answer and the concept(s) formed. Categories evaluated were: total number of responses, apperceptive type, content, reality testing, impulse control, emotional sensitivity, affective expression, emotional maturity, depression, anxiety; experience balance, human response and dependency. Results were expressed as total number of responses and as the clinical description of the main findings. It was applied by two psychologists following the routine procedures used for clinical diagnostic purposes and its analysis was carried out by the same person.

\section{Ana/ysis of results}

Since the predictive form selected those children who formed the cohorts, results of their morbidity and nutritional status were treated as dependent variables. Results of the GHQ-30, Raven and Rorschach tests were considered independent variables. All tests applied to mothers were analyzed clinically; it therefore was not possible to treat the different areas studied by the tests as variables in a multivariate analysis. Different cut-off points were tested to evaluate "best/worst"' groups of children (for morbidity and nutritional parameters, see below) in relation to observations obtained in each of the tests applied to mothers. As for the mothers, they were classified as follows: $>12 /<12$ points in GHQ-30, $>50$ / 50 percentile in the Raven test and normal/"any other category" in the Rorschach test. Morbidity and nutritional parameters were defined on the basis of the information collected during the three consecut1ve surveys: total number of days with symptomatology, total number of episodes, mean number of episodes/ child/year and mean duration of episodes; each of these was calculated for total morbidity, respiratory and diarrhoeic episodes were calculated (Table 1). These results demonstrated that the children studied indeed showed the characteristics expected in subjects selected by the predictor. Nutritional parameters were expressed as mean $\mathrm{Z}$ value of $\mathrm{W} / \mathrm{A}$ and $\mathrm{L} / \mathrm{A}$ at the beginning and at the end of the 6-month survey period, and as mean changes of W/A and L/A during the observation period (Table 2).

Percentages, mean and standard deviation, chi square, Mantel-Haenzsel correction, ANOVA and Student's t-test were calculated with the SAS package (SAS Institute, Cary, North Carolina, USA) at Servicio de Computacion e Informatica (SECI), University of Chile.

\section{Results}

Data was obtained from $103(76.3 \%)$ of the children, while $107(79.3 \%)$ mothers completed the survey, although not all of them answered all the test, as some did not come for the interviews despite repeated invitations. This reluctance to participate in our activities as well as in those programmed by the health 
Table J. Morbidity detected $\mathrm{m}$ high-risk infants.

\begin{tabular}{lr}
\hline Total morbidity & 13.6 \\
$\quad$ Mean no. of episodes/child/year & 10.9 \\
Mean duration of episodes (days) & 24.5 \\
\% of observahon tirne with symptomatology & \\
Respiratory morbidity & 9.0 \\
$\quad$ Mean no. of episodes/child/year & 13.1 \\
Mean duration of ep1sodes (days) & 18.4 \\
\% of observation time with this symptomatology & 4.4 \\
Diarrhoeal morbidity & 5.8 \\
Mean no. of episodes/child/year & 3.5 \\
Mean duration of episodes (days) & \\
\% of observation lime with this symptomatology &
\end{tabular}

centre and other community organizations was also observed in our previous studies (4-6). As in those surveys, families tended to be young (mean age of mothers $=23.1$ years), literacy was high (mean years of schooling for mothers $=9.0$, national mean $=9.0$ years) and a large proportion of families lived as "allegados", i.e. sharing house facilities with friends or relatives $(63.4 \%)$. At the beginning of the survey, no significant differences between the families that participated in the study and those that did not were demonstrated in demographic and socio-economic characteristics and health indicators of children.

Respiratory and diarrhoeal morbidity was similar to that in previous surveys in infants selected by this predictive form (Table 1). In agreement with national statistics which show that moderate and severe forms of malnutrition are presently infrequent in the Chilean infant population (26), mean values of W/A and L/A remained within normal limits throughout the study period (Table 2)

A score of 12 points was obtained in 40/107 mothers (37.4\%) in the GHQ-30 (mean score \pm SD was $10 \pm 6.4$ points, range 1-30). With the Raven test $85 / 105$ $(80.9 \%)$ were below the 50th percentile of IQ distribution, $34 \%$ being below the 25 th percentile. Of the 103 mothers to whom the Rorschach test was applied, $85 \%$ exhibited deviant features in the affective area of personality, although no suggestions of psychotic pathology (deviant verbalizations in reality testing) were detected. The most outstanding characteristics were low intellectual capacity and emotional

Table 2. Mean $\mathrm{Z}$ score values of initial (1) and final ( $r$ ) Length/Age (L/A) and Weight/Age(W/A) and their variations(DIF)during follow up $(n=103)$.

\begin{tabular}{lll}
\hline Variable & Mean \pm SD & Range
\end{tabular}

\begin{tabular}{lcc}
\hline L/A I & $-0.8 \pm 079$ & $-3.1-0.9$ \\
W/A I & $-0.2 \pm 0.94$ & $-2.2-2.7$ \\
L/A F & $-0.7 \pm 1.17$ & $-2.7-2.8$ \\
W/AF & $0.2 \pm 095$ & $-1.8-3.1$ \\
DIF 1/F LIA & $0.8 \pm 1.15$ & $-0.8-4.9$ \\
DIF 1/F W/A & $0.4 \pm 0.89$ & $-0.9-3.2$ \\
\hline
\end{tabular}

immaturity; mothers reacted with hypersensitivity to affective stimuli, but had difficulties in expressing affection and exhibited rigid control of their impulses. They showed concern about other people in an egocentric manner and they were restricted in their interests and in expressing extraversion. In addition, they were not aware of their anxiety, depression and need for dependency.

Children whose mothers' IQ was below the 50th percentile suffered more episodes and days of total morbidity (mean 7.1 episodes vs 6.0 episodes, $p=0.0364$ and mean 76.6 days vs 62.8 days, $p=0.0541$, respectively), and more episodes of diarrhoea (mean 2.0 episodes vs 1.5 episodes, $p=0.0364$ ). Children whose mothers provided an adequate total number of responses in the Rorschach test had Jess morbidity, expressed as total number of days with symptomatology $(p=0.0344)$, total number of episodes $(\mathrm{p}=0.0440)$, days with respiratory symptoms ( $p=0.0226)$, and number of respiratory episodes $(p=0.0300)$. Those infants whose mothers showed a normal personality profile in the Rorschach test tended to have fewer episodes of diarrhoea and these tended to be shorter $(\mathrm{p}=0.0690$ and $p=0.0702$, respectively).

\section{Discussion}

In mothers selected by a previously defined predictive instrument, neurotic traits were considerably more frequent than in the general adult population, of whom it is estimated that approximately $20 \%$ suffer from neurotic symptoms $(9,19)$. As in previous studies, the characteristics of the mother (mainly maternal age and education), the child (nutritional parameters), the family and the household were not associated with higher numbers or longer duration of acute illnesses. Although analysis of these and other variables which may act as confounders did not yield positive findings, results obtained in this study do not exclude the possibility that others may be relevant but remained unidentified.

The low IQ detected in a large proportion of the mothers may make it more difficult to cope with daily facts of life, including health problems. The positivity rate in the GHQ-30 is comparable to that in the preliminary study by Humphreys et al. using the same cutoff point, in which $41.9 \%$ of mothers selected by the predictive mode! were defined as cases, in comparison with $20.5 \%$ observed in a control group of non-selected population (9). The cut-off point $11 / 12$ used in this study

is among the highest reported in the literature and it was selected on the basis of results of Trucco et al. in the Chilean urban poor population (18), and on evidence suggesting that Latins have higher emotional expressiveness. Furthermore, higher cut-off points would have better discriminating capacity among women (19).

The proportion of mothers whose psychological 
profile in the Rorschach test suggested that neurotic pat ology was very high. From the clinical standpoint, deviant features detected were fairly consistent within the group; when we selected the $20 \%$ of children exhibiting the highest frequency or the longest duration of diarrhoeal and respiratory episodes, or the poorest evolution of their anthropometric parameters, the abnormal features in the Rorschach test were similar to those of the whole group, albeit more intense. Results of the psychological evaluation support the hypothesis that presently in the Chilean setting of urban poverty, health risk in infants would be more associated with maternal characteristics than with other factors described in the literature, such as breastfeeding, malnutrition or maternal education $(27,28)$. Methodologies used in this study do not provide information as to how increased morbidity detected inchildren may influence maternal neurosis or how maternal neurotic behaviours may modulate the clinical presentation of illnesses detected in infants, as suggested by others (29).

Until now, governmental "mother and child" programmes have successfully decreased infant mortality and malnutrition in Chile. These activities include different interventions, with emphasis in the widespread distribution of free milk and other foodstuffs to children

of low-income families. During recent years it bas become evident that these interventions have reached their limits of efficiency and that new criteria by which to focus programmes on well-defined families of vulnerable children should now be defined. This study highlights the need for supportive programmes aimed at less privileged families taking into account both the biological characteristics of the infants and the psychological needs of the mothers.

Acknowledgement.1. -We thank Dr J. Pmo. Director of the La Faena Health Centre for the facilities provided to carry out this project and Mr \& Mrs Diaz for stat1stical advice and the analysis of results. This study was supported by FONDECYT. project 91-1068.

\section{References}

1. Albala C. Vio F. Robledo A. Icaza G. La transici6n epidemiolog 1ca en Chile. Rcv Med Chile 1993;121:1446--55

2 Rmmallé, J. Nutriuonal situation of population under 6 years old undercontrol in the health services, Chile, J990-1992. ln: Valiente S. Avila B. editors. Food and nutrition pohcles and programs in Ch1le: a successful experience. Impresora Creces Ltda.: Santiago, Chile. 1993. 161-- 7

3. Araya M. Figueroa G. Espinoza J, Montesinos N, Spencer E. Brunser O. Acute d1arrhoeal d1sease in children under 7 years of age in a periurban sium of Santiago, Chile. J Hyglene 1985.95:457-67

4. Araya M. Baiocchi N. Espinoza J, BrunserO. Persistent d1arrhoea in the commumty. Characterisucs and nsk factors. Acta Paediatr Scand 1991;80:181-9

5. Araya M, Espinoza J, Brunser 0, Pacheco 1, Cruche! S. Aplicac1on de un modelo pred1ct1vo en mnos de mvef socioecon6mico baJo. Rev Med Chile 1992;120:342--8
6. Araya M, Espmoza J, Brunser 0, Cruchet S. Elfect of health education and primary care on diarrhoeal disease morbid1ty rn children: evaluation of a predictive mtervention mode!. J Diarrhoeal Dis Res 1994;12:103.. 7

7. Goldberg DP. The detection of psychiatrie illness by quesuonnairc: a technique for the identification and assessment of nonpsychotic psych1atnc 11lness. London- Oxford University Press.

8. Goldberg DP, Kay C, Thompson L. Psychiatrie morb1d1ty in general pract1ce and the community. Psycho( Med 1976;6:565-9

9. Humphreys D, Araya M. Espmoza J, Brunser O. Pacheco J Evaluat1on of maternai mental health in high nsk infants. J Public Health 1996.30. In press

10. Harre! FE. The log1stic procedure SUGI S.A.S. Supplemental library User's guide. S.A.S. Inc: Cary, North Carohna, 1983

11. Murrels TJ, Smith TMF. Catford JC. Machin D. The use oflogit models 10 investigate social and biolog1cal factors $\mathrm{m}$ mfant mortality. 1. Methodology. Statist Med 1985;4:175-87

!2. Machm D. Murrels TJ. Calford JC. Smith TMF. The use oflogll models to investigale social and biological factors in mfant mortality. Il. Neonatal mortality. Stallst Med 1986;5:139-53

13. BrunserO. Espmoza J, Araya M. PachecoJI. Cruchet S. Chronic iron intake and diarrhoeal d1sease $\mathrm{m}$ infants. A field study ina lessdeveloped country. Eur J Chn Nutr 1993;47:317-26

14. Espinoza J, Araya M, Cruche! S. Pacheco JI. Cordano A, Brunser O. Rap1d refeeding with rice-based formulae of patients with acute diarrhoea. A field !rial. Int J Food Sc1 Nutr 1992;43:139-46

15. Graffar M. Etude d'agglomeration en cinq cent famillt.-s d'une commune de l'agglomeration bruxelloise. Laborato!fe de Medicme Sociale, Université Libre de Bruxelles. Brussels. Belgium.

1957

16. Alvarez Wurgaft F. Salazar ME. Mediciones de nivel socioeconomico bajo urbano en familias con lactantes desnutridos. Arch Latinoam Nutr 1982;32.325-31

17 Hamill PV. Drizd TA. Johnson CH, Reed RD. Roche AF, Moore W. Phystcal growth: National Center for Health Statistics. Am J Chn Nutr 1982;32:325 31

18. Trucco M, Campusano ME. Larrain S. Un cuestionario para detectar des6rdenes emoclonales. Estudio de validaciôn preliminar. Rev Chtl Neuro-Psiquiatr 1979;17.20-4

19. Mari JJ, Williams P. Misclassificatron by psychiatrie screening questionnaires. J Chron Dis 1986:39:371-8

20. Tarnopolsky A, Hand DJ. Mclean EK. Roberts H Wiggings RD. Validity of uses of a screemng questionnaire (GHQ) in the community. Br J Psychiatry 1979;134:508-15

21. Araya R, Wynn R, Lewis G. Companson of two self-administered psychiatrie questionnaires(GHQ-12 and SRQ-20) in primary care m Ch1le. Soc Psychiatrie Psychiatr-Ep1demiol 1992;27:168- 73

22. Dohrenwend BP. Dohrenwend BS. Perspective on the past and future of psychiatrie epldemiology: the 1981 Rema Lapouse Lecture. Am J Pubhc Health 1982;72:1271-74

23. Raven JC. Test de matnces progresivas para la capacidad mtelectual manual. Buenos Aires: Editorial Pa1dos, 1950

24. Klopfer B. Kelly D. Técnica del psicodiagn6stico de Rorschach. Buenos Aires: Editorial Paidos. 1977

25. Portuondo J. El psicodiagnostico de Rorschach en psicologia climca. Madrid. Biblioteca Nueva, 1976

26. Ministerio de Salud. Anuano I003. 1995

27. Mata LJ. The ch1ldren of Santa Maria Cauqué. A prospective field study of health and growth. Cambridge. MA: MIT Press, 1978

28. Persistent diarrhoea in children in developing countries. Geneva: WHO. WHO/CDD/88.27, 1988

29. Ze1tlin M, Ghassem H, Mansour M. Positive deviance and child nutrition-with emphasis on psychosocial and behavioural aspects and implications fordevelopment. Tokyo: United Nations University. 1990

Received Feb. 9, 1995. 